\title{
Electrochemical Investigations on Semi-conducting Properties of a Passive Film on Conducting Polypyrrole Coated Low Carbon Steel in a Simulated Concrete Pore Solution
}

\author{
H. Munot ${ }^{a}$, P. Deshpande ${ }^{a, *}$ and C. Modhera ${ }^{b}$ \\ ${ }^{a}$ College of Engineering, Pune, 411005, India \\ ${ }^{b}$ Sardar Vallabhbhai National Institute of Technology, Surat, Gujarat, 395007, India
}

Received June 24, 2017; accepted March 22, 2018

\begin{abstract}
Conducting polypyrrole was synthesized by the chemical oxidative method, and characterized using FTIR spectroscopy. An epoxy based paint containing conducting polypyrrole was prepared and applied on a low carbon steel sample, using a film applicator. The uncoated and painted steel samples were kept immersed in the simulated concrete pore solution. The Mott-Schottky technique was used to study the passive film formation on an uncoated low carbon steel, and the conducting polypyrrole coated low carbon steel was immersed in a simulated pore solution. The peaks at $1447 \mathrm{~cm}^{-1}$ and $1149 \mathrm{~cm}^{-1}$ are the responsible peaks of protonated nitrogen atoms in polypyrrole. The peak at $1538 \mathrm{~cm}^{-1}$ refers to the $\mathrm{C}-\mathrm{C}$ stretching vibration in the pyrrole ring, and the peak at $1042 \mathrm{~cm}^{-1}$ denotes the $\mathrm{C}-\mathrm{H}$ stretching vibration in the pyrrole ring. The M-S slope indicates that the passive film on uncoated low carbon steel exhibited n-type semi-conductive behaviour, and that the polypyrrole coating exhibited $\mathrm{p}$ - $\mathrm{n}$ type behaviour. However, with the increasing chloride contents and immersion time, the polypyrrole coating exhibited only $\mathrm{p}$ type behaviour.
\end{abstract}

Keywords: corrosion, passive film, concrete pore solution, rebar and conducting polypyrrole.

\section{Introduction}

Steel reinforcement in concrete is corrosion protected, as long as the passive film remains stable on its surface. High alkalinity $(\mathrm{pH} \sim 13)$, due to high hydroxide concentration of the concrete pore solution, is responsible for the formation of a passive film on the rebar. However, the passive film gets damaged due to chloride attack, and or by carbonation, therefore, corrosion begins [1].

During the last two decades, rebar corrosion protection has been the subject of a large number of electrochemical investigations, including passive film

\footnotetext{
* Corresponding author. E-mail address: pravinpd@hotmail.com
} 
characterization studies. Zhang Yun-Lian et al. studied the electronic properties of passive films on a rebar, in a simulated concrete pore solution, as well as the effect of chloride ions and mineral admixtures in a concrete pore solution. It was observed that the addition of chloride ions in solutions significantly decreased the Mott- Schottky slopes, and caused an increase in donor density. It was also found that the application of proper quantity mineral admixtures in concrete could inhibit film breakdown, and delay pitting initiation [2]. Jon Williamson et al. studied the effect of the composition of a simulated concrete pore solution and chlorides on the electronic properties of passive films on a carbon steel rebar. It was found that the passive film showed n-type semiconductive behavior, with two discrete donor species and high donor densities. Deep donor densities increased with an increase in passivation time. Less protective films resulted in lower values of space charge capacitance and flat band potentials [3]. Yujie Zhang et al. studied the semi conductive behavior of the passive film on carbon steel in a simulated concrete pore solution under stress. It was noted that, irrespectively of the type and magnitude of the applied load, the passive film on the rebar displayed n- type behavior, and the chloride concentration decreased the Mott-Schottky slopes [4]. L. Hamadou et al. characterized passive films formed on low carbon steel in a borate buffer solution. It was observed that a stable passive state appeared over a potential range from -0.2 to $0.9 \mathrm{~V}$, and that the passive film exhibited $\mathrm{n}$ type behavior [5]. To protect the rebar from corrosion, various methods have been attempted, such as the use of high performance concrete, low water/cement ratio, optimum thickness of the concrete cover, use of corrosion inhibitors, application of cathodic protection, and use of galvanizing and epoxy coatings [6].

Unfortunately, coated rebars are prone to mechanical damage during handling and installation, and to subsequent corrosion. Recently, conducting polymers, such as polyaniline and polypyrrole, have emerged as non-toxic and anticorrosive pigments. Novelty of these conducting polymer based coatings is that, in the case of damage, a passive film gets regenerated, and protects the underlying metal from further corrosion [7].

We have recently shown the use of conducting polypyrrole based paints for the rebar protection against chloride induced corrosion. The polypyrrole coated steel sample was able to protect low carbon steel for up to 240 hours of immersion in the pore solution without chlorides, and in the pore solution, with $0.25 \mathrm{M} \mathrm{NaCl}$. However, at $0.5 \mathrm{M} \mathrm{NaCl}$ and at higher concentrations, the self-healing property of the polypyrrole coating is no longer able to protect the steel sample from corrosion [8]. Since the stable passive film plays an important role in corrosion protection, we extended this work, and have used Mott-Schottky technique to study the semi-conducting properties of the passive film on the conducting polypyrrole coated low carbon steel in a simulated concrete pore solution, and the results are reported. 


\section{Experimental study}

\section{Conducting polypyrrole based paint preparation}

Conducting polypyrrole was synthesized by the method adapted by V. Truong et al. [9], and conducting polypyrrole based paints were prepared by the method described by P. Deshpande et al. [10], and elaborated as follows. Conducting polypyrrole $(2 \mathrm{~g})$ as a pigment, $12 \mathrm{~g}$ of Xylene, $8 \mathrm{~g}$ of titanium dioxide $\left(\mathrm{TiO}_{2}\right)$ and $8 \mathrm{~g}$ of bis-(2-ethylhexyl) phthalate (dioctyl phthalate: DOP) were added to the solution with $70 \mathrm{~g}$ of epoxy resin (GY 250 supplied by Huntsman Advanced Materials (India) Pvt Ltd. Andheri (East), Mumbai- 400093, India). The mixture was ball-milled for 16 hours (Ball mill supplied by Indo German Industries, Daman, India. Drive motor: Crompton Make - 2HP, $1440 \mathrm{rpm}, 415$ V, $50 \mathrm{~Hz}$ ). The purpose of adding titanium dioxide and Di-octyl phthalate to epoxy resin was to improve viscosity and elastic properties of paint. Xylene was used as a solvent for the paint formulation. The paint was filtered through fine cotton, and applied on the low carbon steel samples (AISI 1015 supplied by Rajasthan steels, Pune, India) by a film applicator, to keep paint thickness $(60 \mu \mathrm{m})$ uniform on the entire surface. Finally, the painted low carbon steel samples were cured in air, at ambient temperature, for 24 hours.

\section{Preparation of a simulated pore solution}

The electrolyte used for immersion should be an exact representative concrete pore solution, with $\mathrm{Ca}^{+}, \mathrm{K}^{+}$and $\mathrm{Na}^{+}$ion additions [11]. The chemical composition of the simulated concrete pore solution is shown in Table 1. One solution without chloride and three solutions with increasing chloride contents -0.25 $\mathrm{M} \mathrm{NaCl}, 0.5 \mathrm{M} \mathrm{NaCl}$ and $1 \mathrm{M} \mathrm{NaCl}$ - were prepared.

Table 1. Chemical composition of the simulated concrete pore solution.

\begin{tabular}{|c|c|c|}
\hline Compound & Mol.L & Weight in grams per 100 mL of water \\
\hline $\mathrm{NaOH}$ & 0.1 & 0.4 \\
\hline $\mathrm{KOH}$ & 0.3 & 1.68 \\
\hline $\mathrm{Ca}(\mathrm{OH})_{2}$ & 0.03 & 0.22 \\
\hline $\mathrm{CaSO}_{4} . \mathrm{H}_{2} \mathrm{O}$ & 0.002 & 0.03 \\
\hline
\end{tabular}

\section{Characterization}

Conducting polypyrrole was characterized using a Fourier Transmission Infra Red Spectrometer (FTIR- 4100 JASCO, Japan).

\section{Electro-chemical studies}

A corrosion cell with a three electrode geometry of paint coated samples as working electrode $\left(8 \mathrm{~cm}^{2}\right)$, platinum as counter electrode, and saturated calomel (SCE: pH Products, Hyderabad, India) as reference electrode was used. The cell was coupled with a Gamry reference system 1000 (Wilmington, USA) for MottSchottky plots. All measurements were carried out five times to obtain good results reproducibility. The Mott-Schottky measurements were monitored for bare carbon steel samples, and the polypyrrole coated samples were immersed for 240 hours in a chloride free concrete pore solution, and in a concrete pore solution with fixed chlorides amounts. 


\section{Results and discussion}

The FTIR spectrum of conducting polypyrrole is shown in Fig. 1.

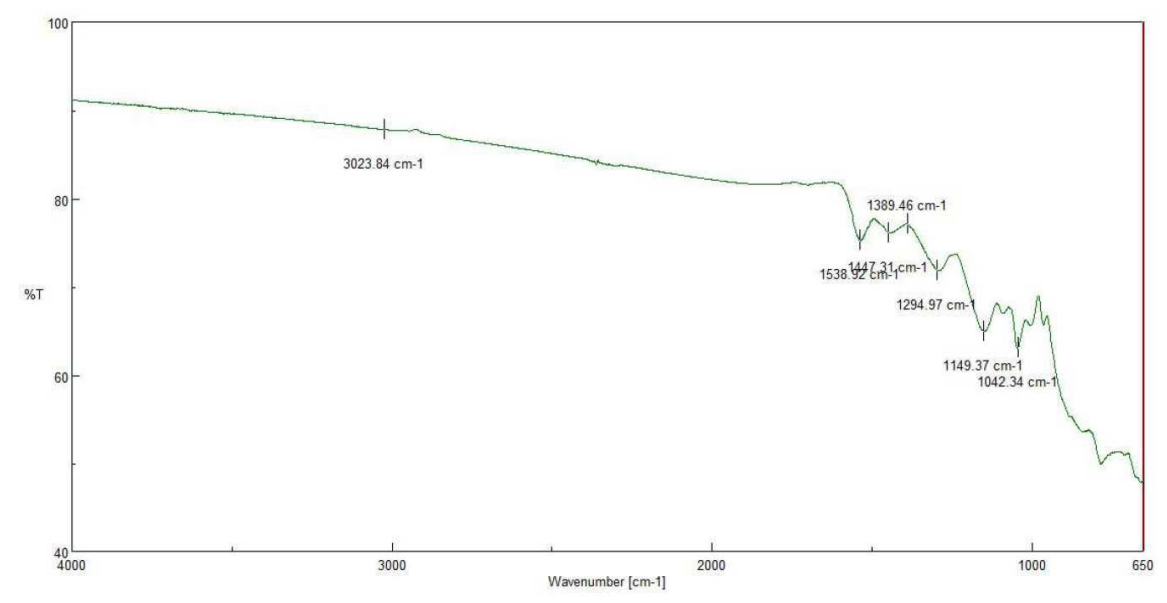

Figure 1. FTTR spectrum of conducting polypyrrole.

The peaks at $1447 \mathrm{~cm}^{-1}$ and $1149 \mathrm{~cm}^{-1}$ are the responsible peaks of protonated nitrogen atoms in polypyrrole. The peak at $1538 \mathrm{~cm}^{-1}$ refers to the C-C stretching vibration in the pyrrole ring, and the peak at $1042 \mathrm{~cm}^{-1}$ denotes the $\mathrm{C}-\mathrm{H}$ stretching vibration in the pyrrole ring [12].

\section{Mott-Schottky analysis}

The formation of a passive film in the concrete pore solution takes place in two stages: initially, ferrous hydroxide is formed on the rebar surface; subsequently, it gets converted into the more stable ferric oxide $-\gamma \mathrm{Fe} \mathrm{OOH} \mathrm{[1].} \mathrm{The} \mathrm{results} \mathrm{of}$ the Mott-Schottky studies are depicted in Figs. 2 to 5, for uncoated steel samples, and in Figs. 6 to 9, for polypyrrole coated steel samples.

Fig. 2 shows Mott-Schottky plot of uncoated steel, just after immersion in a concrete pore solution without chloride.

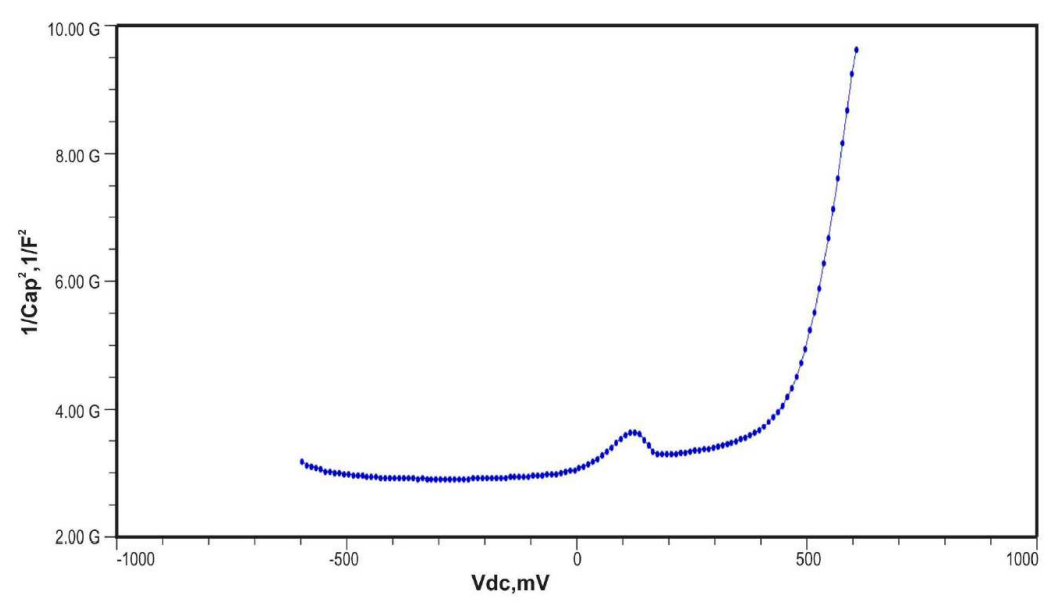

Figure 2. Mott-Schottky plot of uncoated steel in a concrete pore solution, just after immersion. 
Figs. 3 to 5 show Mott-Schottky plots of uncoated steel after 72 hours, 168 hours and 240 hours of immersion in a concrete pore solution with no chlorides addition, and $0.25 \mathrm{M}, 0.5 \mathrm{M}$ and $1 \mathrm{M}$ chlorides addition, respectively.

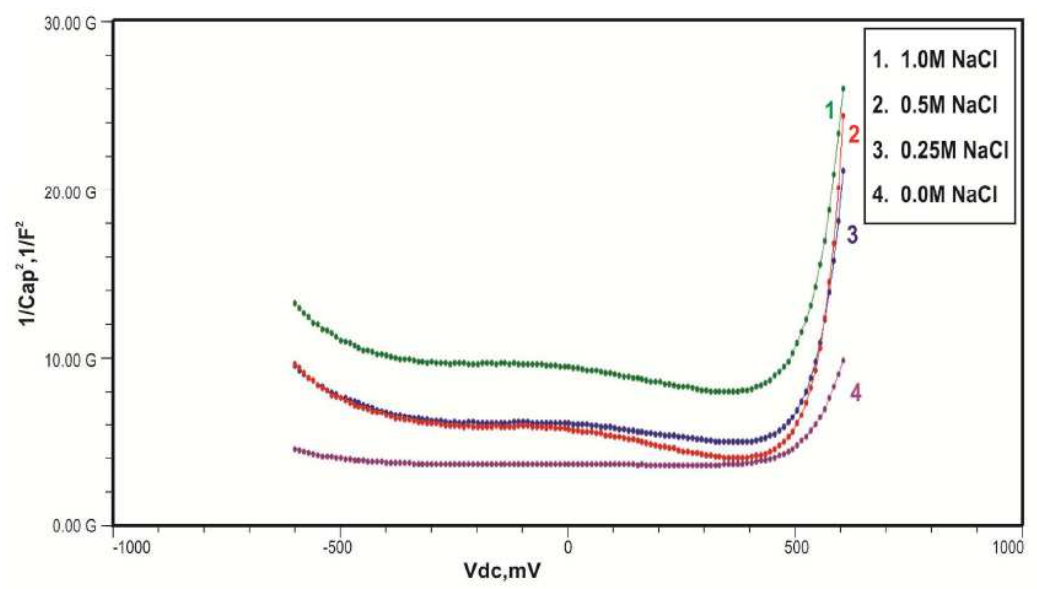

Figure 3. Mott-Schottky plot of uncoated steel, after 72 hours of immersion in a concrete pore solution.

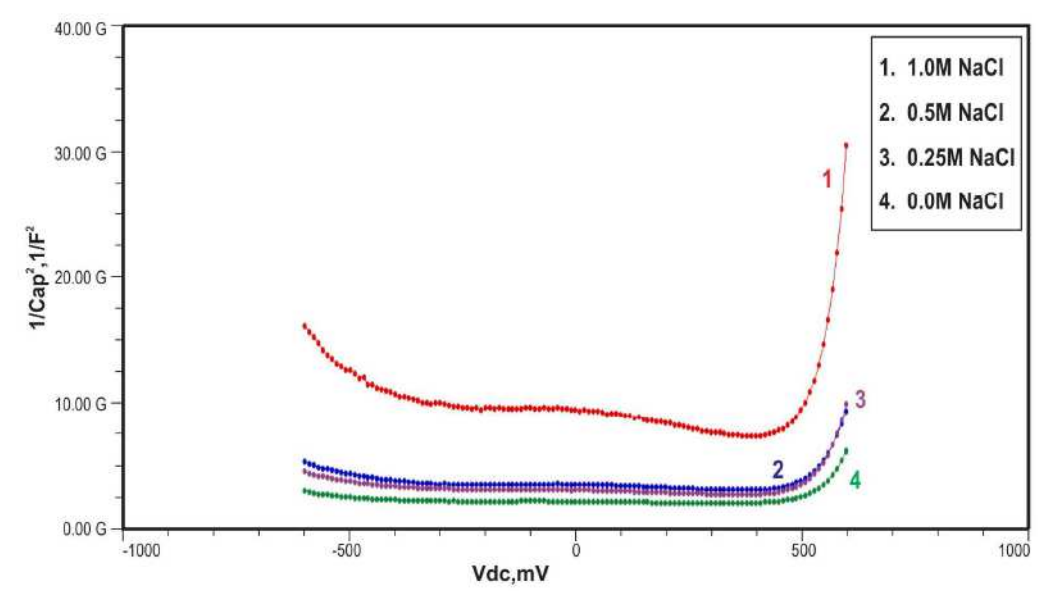

Figure 4. Mott-Schottky plot of uncoated steel, after 168 hours of immersion in a concrete pore solution.

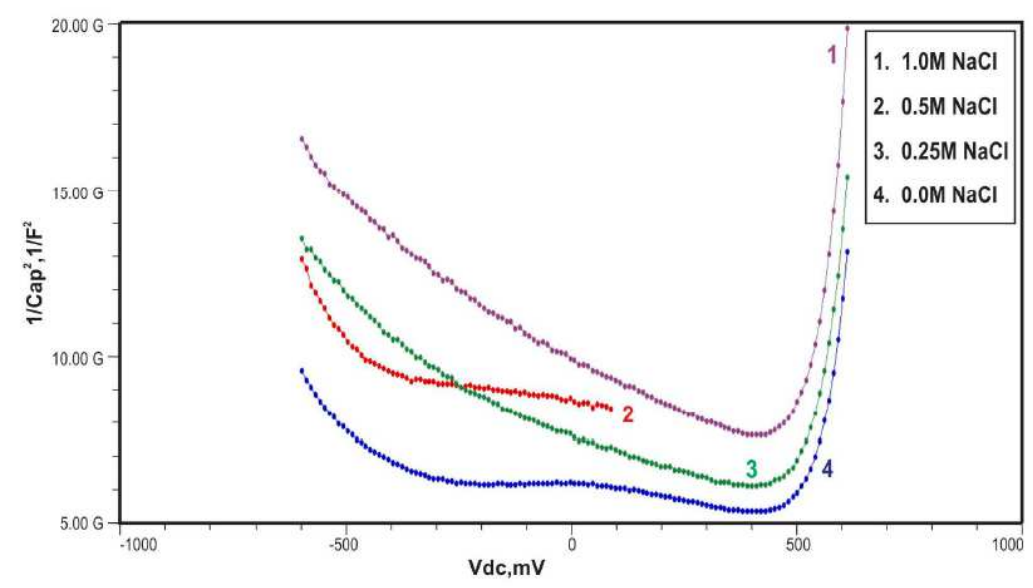

Figure 5. Mott-Schottky plot of uncoated steel, after 240 hours of immersion in a concrete pore solution. 
The slopes of all M-S plots, depicted in Figs. 2 to 5, are positive, indicating $\mathrm{n}$ type behavior of the passive film. It seems that the essential features of the passive films' M-S plots formed in various solutions did not change, compared to the just after immersion condition. The passive film still exhibited n-type behavior. These results are in good agreement with previous work [2].

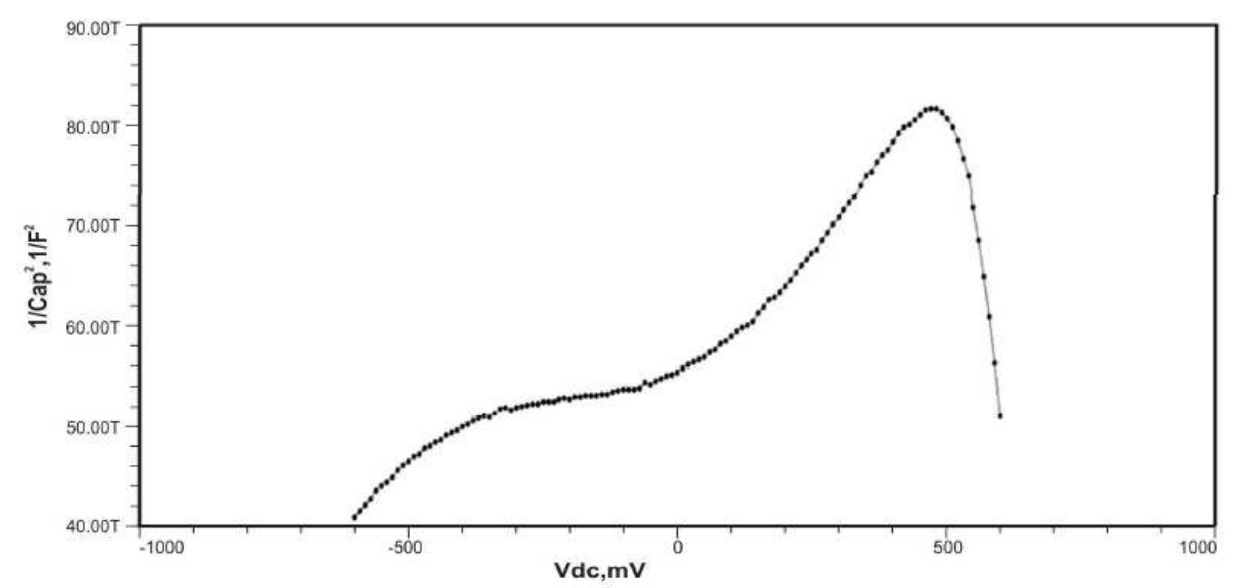

Figure 6. Mott-Schottky plot of polypyrrole coated steel, just after immersion in a concrete pore solution.

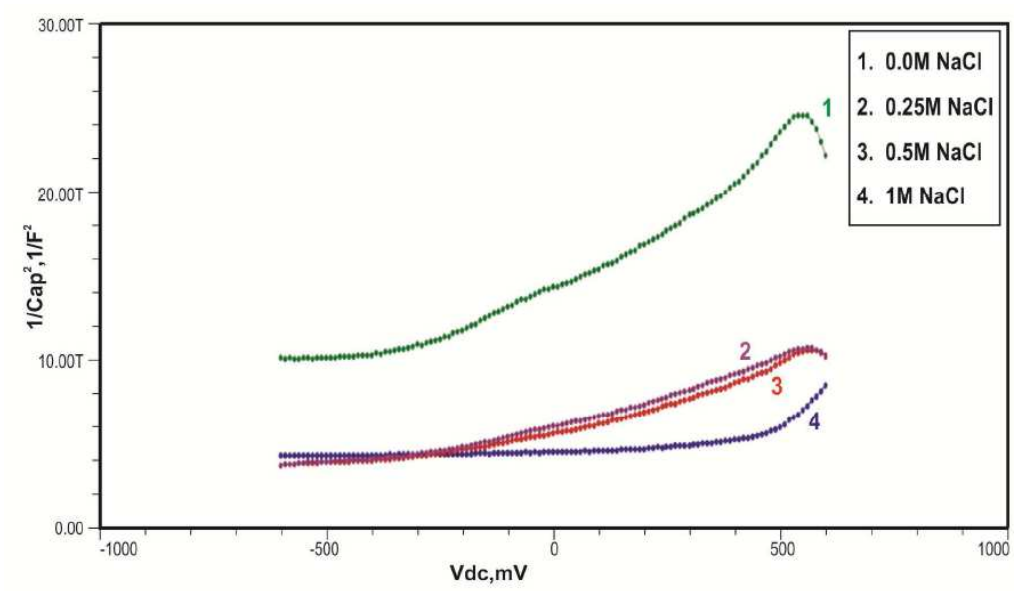

Figure 7. Mott-Schottky plot of polypyrrole coated steel, after 72 hours of immersion in a concrete pore solution.

Initially, the slope of the M-S plot in the case of the polypyrrole coated sample is positive, indicating $\mathrm{n}$ type behavior of the passive film. However, beyond $0.5 \mathrm{~V}$, a transition from a positive to a negative slope, i.e., $\mathrm{n}$ type to $\mathrm{p}$ type, was observed. At 72 hours of immersion in a concrete pore solution, no such change from $n$ to $p$ type was observed, except in the solution without chloride. After 168 hours and 240 hours of immersion, no transition from $n$ type to $p$ type was noted, in the case of the solutions with 0.5 and $1 \mathrm{M} \mathrm{NaCl}$, and in all solutions, respectively. In previous work, it was found that the polypyrrole coated steel sample was able to protect low carbon steel for up to 240 hours of immersion in the pore solution without chlorides, and in the pore solution with $0.25 \mathrm{M} \mathrm{NaCl}$. 
However, at $0.5 \mathrm{M} \mathrm{NaCl}$ and higher concentrations, the self-healing property of the polypyrrole coating was no longer able to protect the steel sample from corrosion. Conducting polypyrrole coating can protect plain carbon steel from corrosion by several mechanisms - barrier protection, passive film formation, controlled inhibitor release mechanism, or by generation of an electric field [7-8].

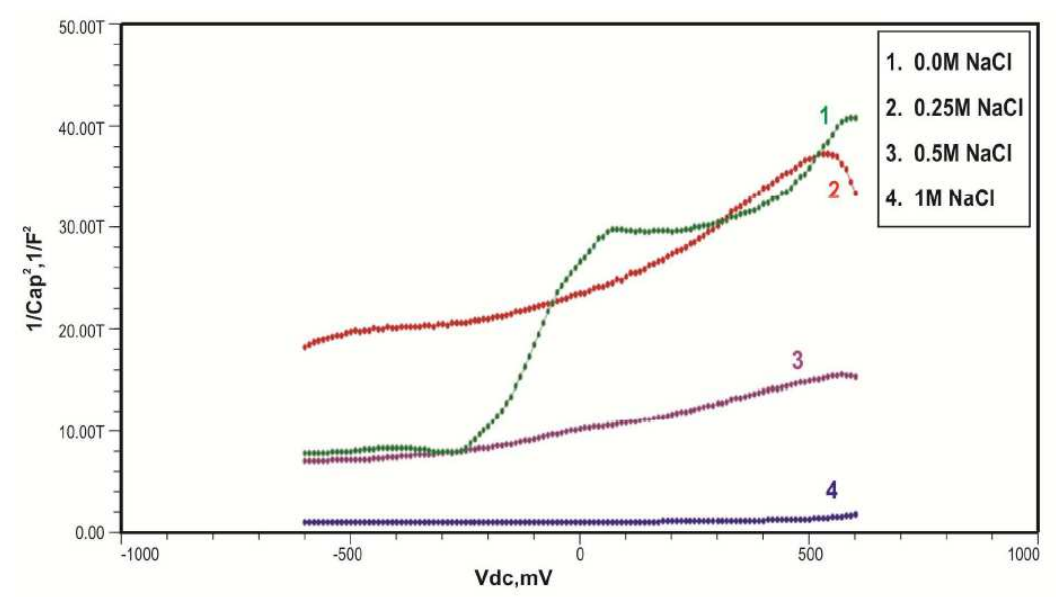

Figure 8. Mott-Schottky plot of polypyrrole coated steel, after 168 hours of immersion in a concrete pore solution.

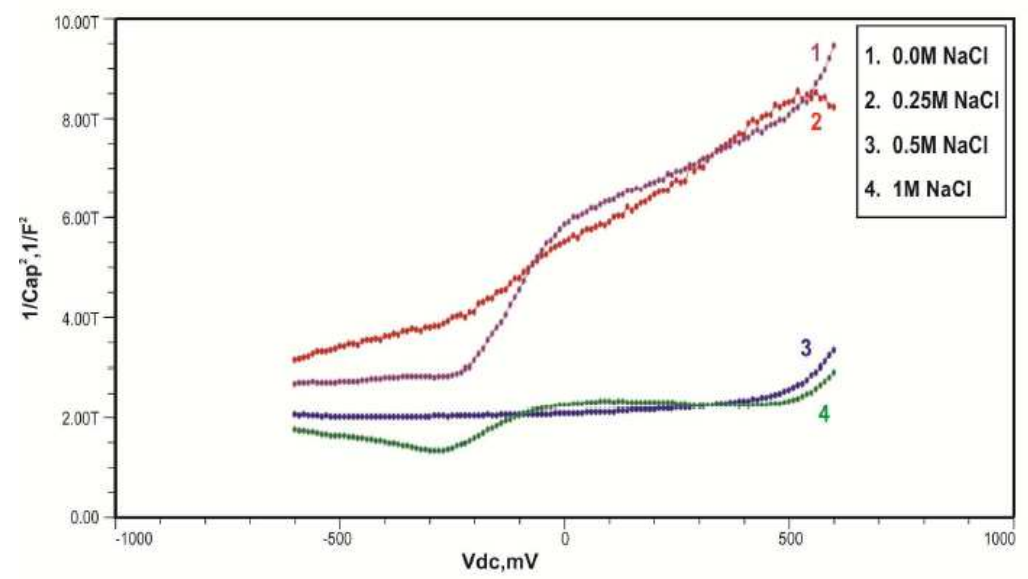

Figure 9. Mott-Schottky plot of polypyrrole coated steel, after 240 hours of immersion in a concrete pore solution.

\section{Conclusion}

The M-S slope indicated that the passive film on uncoated low carbon steel exhibited n-type semi-conductive behaviour, and that the polypyrrole coating exhibited $\mathrm{p}-\mathrm{n}$ type behaviour. However, with the increasing immersion time in a concrete pore solution up to 240 hours, and chloride contents up to $1 \mathrm{M} \mathrm{NaCl}$, the polypyrrole coating on low carbon steel only exhibited p type behaviour.

\section{Acknowledgments}

The authors thank Prof. N.B. Dhokey, Head of the Department of Metallurgy and Materials Science, College of Engineering, Pune (M.S.), for providing facilities, 
and Prof. B. B. Ahuja, Director of the College of Engineering, Pune, (M.S.), for his encouragement.

\section{References}

1. Bentur A, Diamond S, Berke NS. Steel corrosion in concrete: Fundamentals and Civil Engineering Practice. $1^{\text {st }}$ ed. London: E \& FN Spon; 1997.

2. Yun-Lian Z, Qi-Ling L. Electrochemical study on semiconductive properties of the passive film on rebar in concrete. J Zhejiang Univ Sci A. 2006;7:1447.

3. Williamson J, Isgor OB. The effect of simulated concrete pore solution composition and chlorides on the electronic properties of passive film on carbon steel rebar. Corros Sci. 2016;106:82.

4. Zhang Y, Poursaee A. Study of the semi-conductive behavior of the passive film on carbon steel in simulated concrete pore solution under stress. Anti-Corrosion Methods Mater. 2015;62:363.

5. Hamadou L, Kadri A, Benbrahim N. Characterization of passive films formed on low carbon steel in borate buffer solution $(\mathrm{pH} 9.2)$ by electrochemical impedance spectroscopy. Appl Surf Sci. 2005;252:1510.

6. Kumar V. Protection of steel reinforcement for concrete: A review. Corros Rev. 1998;16:318.

7. Deshpande P, Sazou D. Corrosion protection of Metals by Intrinsically Conducting Polymers. Boca Raton:CRC Press; 2015.

8. Munot H, Deshpande P, Modhera C. Effects of chloride ions on the corrosion resistance of conducting polypyrrole coated steel in simulated concrete pore solution. UPB Sci Bull.2017;79.

9. Truong V, PLai P, Moore B, et al. Corrosion protection of magnesium by electro active polypyrrole / paint coatings. Synth Metals. 2000;110:7.

10. Deshpande P, Vagge S, Jagtap S, et al. Conducting polyaniline based paints on low carbon steel for corrosion protection. Protection Metals Phys Chem Surf. 2012;48: 356.

11. Poursaee A. Corrosion of steel bars in saturated $\mathrm{Ca}(\mathrm{OH})_{2}$ and concrete pore solution. Concrete Research Lett. 2010;1: 90.

12. Selvaraj M, Palraj S, Rajagopal G, et al. Polypyrrole as a protective pigment in organic coatings. Synth Metals. 2008;158:894. 